\title{
QUALIDADE FISIOLÓGICA E ARMAZENAMENTO DE SEMENTES DE ALGODÃO EMBEBIDAS EM SOLUÇÃO DE CLORETO DE MEPIQUAT
}

\author{
Physiological quality and storage of cotton seeds soaked in mepiquat chloride solution
}

\author{
Getúlio Takashi Nagashima', Édison Miglioranza², Celso Jamil Marur³ , Ruy Seiji Yamaoka ${ }^{3}$, \\ Alberto S.R. Barros ${ }^{3}$, Fernanda Marchiotto ${ }^{4}$
}

\begin{abstract}
RESUMO
Após tratamento de sementes, é comum a semeadura não ocorrer imediatamente. Eeste trabalho, objetivou-se determinar o efeito do armazenamento de sementes de algodão embebidas com regulador de crescimento Cloreto de Mepiquat (CM) na qualidade fisiológica e manutenção do seu efeito como fitorregulador. Sementes da cultivar IPR 120 foram embebidas em soluções com CM nas doses de 2,5; 5,0 e 10,0 g i.a. $\mathrm{kg}^{-1}$ de sementes por 12 horas e secas a sombra em local ventilado, e testemunha sem tratamento. A avaliação foi feita por meio dos testes de germinação após armazenamento de 0, 30, 60, 90 e 180 dias após o tratamento (DAT). Aos 60 DAT foi avaliado o comprimento de plântulas, em rolo de papel, e a altura da planta, da inserção do nó cotiledonar, da área foliar e a massa da matéria seca de folhas e caule avaliada depois de um período de 24 dias após a emergência das plântulas cultivadas em vasos. O delineamento experimental foi o inteiramente casualizado com vinte tratamentos e quatro repetições, em esquema fatorial (4 doses e 5 tempos de armazenamento), para avaliar o teste de germinação. As sementes embebidas em cloreto de mepiquat podem ser armazenadas por pelo menos 60 dias, sem redução na sua qualidade fisiológica e mantendo o efeito redutor no crescimento das plantas, apresentando crescimento menor, antes mesmo da emergência e persiste por, pelo menos, 180 dias após o tratamento.
\end{abstract}

Termos para indexação: Gossypium hirsutum L., regulador de crescimento, tratamento de sementes, persistência no efeito.

\begin{abstract}
Sowing is not usually possible immediately after seed treatment. This work was aimed at determining the effect of the storage of cotton seeds soaked with mepiquat chloride (growth regulator) on physiological quality and maintenance of this effect as a plant regulator. Cotton seeds from cultivar IPR 120 were soaked in solutions with mepiquat chloride in doses of zero (control), 2,5: 5,0 and $10,0 \mathrm{~g}$ a.i. $\mathrm{kg}^{-1}$ of seeds for 12 hours and dried in the shade in an aerated place. The evaluation was done through germination at zero, 30, 60, 90 and 180 days after the treatment (DAT). 60 DAT the seedling length was evaluated in paper rolls. Seeds stored for 60 DAT were cultivated in pots and plant height and cotyledonary knot insertion, foliar area and dry mater of leaf and branch were appraised for a period of 24 days after emergence. The experimental design was completely randomized with twenty treatments and four replications, using a random factorial (four doses and five time of storage). There was no emergence capacity and vigor loss up to 60 DAT and the effect of the plant regulator on plant height and cotyledonary knot insertion was maintained. Seeds soaked in mepiquat chloride can be stored for at least 60 days without physiological quality reduction and maintaining the reducing agent effect on plant growth, showing lower growth, even before the emergence, lasting for at least 180 days after treatment.
\end{abstract}

Index terms: Gossypium hirsutum L., growth regulator, seed treatment, persistence on the effect.

(Recebido em 08 de outubro de 2008 e aprovado em 26 de junho de 2009)

\section{INTRODUÇÃO}

Uma das estratégias agronômicas para o aumento da produtividade do algodoeiro é o manejo das plantas com reguladores de crescimento (Hodges et al., 1991). Os reguladores de crescimento são substâncias químicas naturais ou sintéticas e, quando aplicadas diretamente nos vegetais, alteram os processos vitais ou estruturais, por meio de modificações no balanço hormonal das plantas, podendo aumentar a produção, melhorar a qualidade ou facilitar a colheita (Laca-Buendia, 1989; Lamas, 2001).

Com o surgimento de novas cultivares, da utilização de semeadura adensada e colheita mecânica na cultura do algodoeiro, tornou-se imprescindível o manejo com reguladores de crescimento, reduzindo o porte e a arquitetura, facilitando as pulverizações para controle de pragas e doenças e proporcionar maior precocidade na produção.

\footnotetext{
${ }^{1}$ Universidade Estadual de Londrina/UEL - Centro de Ciências Agrárias/CCA - Departamento de Agronomia - Cx. P. 6001 - $86051-990$ - Londrina, PR gtnagashima@yahoo.com.br

2Universidade Estadual de Londrina/UEL - Centro de Ciências Agrárias/CCA - Departamento de Agronomia- Londrina, PR

${ }^{3}$ Instituto Agronômico do Paraná/IAPAR - Área de Ecofisiologia - Londrina, PR

${ }^{4}$ Engenheira Agrônoma - Autônoma - Londrina, $\mathrm{Pr}$
} 
Entretanto, essas técnicas culturais atualmente disponíveis não são suficientes para que as plantas alcancem estaturas indicadas por Righi et al. (1965) que preconiza a altura máxima do algodoeiro de 1,5 vezes o espaçamento entre linhas utilizadas na semeadura. Atualmente, as cultivares disponíveis no mercado apresentam porte superior a 1,20 m, as técnicas e as épocas de pulverização foliar dificultam a obtenção do porte adequado à introdução do adensamento na cultura, havendo, assim, necessidade de desenvolvimento de tecnologias de aplicação que permitam a redução do porte da planta o mais cedo possível.

O uso da embebição de sementes de algodão com cloreto de mepiquat (CM) torna-se uma tecnologia para obtenção de plantas com menor estatura, e esta redução no porte ocorre desde a emergência (Nagashima et al., 2005).

Alguns pesquisadores têm utilizado tratamentos das sementes com hormônios para atender a determinadas finalidades. Corbin \& Frans (1991) embeberam sementes de algodão com CM e chlormequat, para a redução do efeito negativo do uso de herbicida Fluometuron e Xu \& Taylor (1992) para modificação dos padrões do enraizamento e aumento da resistência de plântulas de algodão ao estresse hídrico. Nagashima et al. (2005), embebendo sementes de algodão por 3, 6 e 12 horas e concentrações de CM (0; 0,5; 2,5; 5,0 e 7,5\%) concluíram que o efeito redutor é relativo ao tempo de embebição e dose utilizada. Em condições de campo, quando semeados em espaçamentos de 0,60 m entre linhas, a produtividade se mantém sem alteração com a embebição de sementes com CM (Nagashima et al., 2007).

O tratamento de sementes de algodão via embebição é um método menos prático do uso de regulador, pois requer imersão, secagem e armazenamento antes da semeadura (Yeats et al., 2005) e erros em algum destes procedimentos podem causar detrimentos na qualidade de sementes.

Portanto, a embebição de sementes de algodão deve ser efetuada com certa antecedência, aproximadamente uma semana antes da semeadura, pelos produtores e mesmo após o tratamento, nem sempre é possível efetuar a semeadura imediatamente. Para empresas produtoras de sementes, o tratamento deverá ser com, pelo menos, 60 dias de antecedência.

Baseados nos imprevistos e necessidades citadas, neste trabalho, objetivou-se avaliar a aplicação de CM, eficiência e persistência dos efeitos durante o armazenamento, na redução do porte das plantas de algodão, quando aplicado via embebição de sementes, bem como a influência do tratamento na qualidade fisiológica dessas sementes.

\section{MATERIAL E MÉTODOS}

O experimento foi conduzido no Instituto Agronômico do Paraná (IAPAR) - Lat.: 23²9'41,4"S, Long.: $51^{\circ} 12^{\prime} 5,5^{\prime \prime}$, no município de Londrina, Paraná, Sul do Brasil em laboratório e casa de vegetação, utilizando sementes de algodão da cultivar IPR 120 que apresenta ciclo até colheita de 152 dias e porte médio e arquitetura tipo taça, deslintadas quimicamente com ácido sulfúrico. Um quilograma de sementes foi embebido por submersão em $550 \mathrm{~mL}$ da solução de CM nas concentrações de 2,5; 5,0 e 10,0 g i.a. $\mathrm{kg}^{-1}$ de sementes, na temperatura de $20^{\circ} \mathrm{C}$, por 12 horas e secas à sombra em local ventilado e semente sem tratamento (zero) como testemunha. Após este procedimento, as sementes foram acondicionadas em sacos de papel "kraft" e armazenadas em condições de ambiente.

Para avaliar a qualidade fisiológica das sementes, realizou-se teste de germinação, conforme as Regras de Análise de Sementes - RAS (Brasil, 1992), nos tempos 0, 30, 60, 90 e 180 dias após tratamento (DAT). Foi realizado o teste de comprimento de plântulas aos 60 DAT e a semeadura em vasos aos 60 e 180 DAT para verificação da manutenção do efeito redutor após o armazenamento.

\section{Germinação}

As sementes foram distribuídas em papel Germitest na forma de rolos, umedecido na proporção de duas vezes e meia o volume de água em relação ao peso do papel seco. Os rolos foram colocados em germinador, regulado com temperatura constante de $25^{\circ} \mathrm{C}$. As avaliações foram feitas aos três dias após a instalação do teste e resultados foram expressos em porcentagem média de plântulas normais por tratamento. Foram utilizadas quatro repetições de 50 sementes para cada tratamento.

\section{Comprimento da radícula e do hipocótilo}

Foi utilizado o método de rolo de papel, umedecido na proporção de duas vezes e meio o volume de água em relação ao peso do papel seco. Na montagem, as sementes (com tamanhos uniformes, para minimizar a variância do erro experimental) foram depositadas sobre duas folhas de papel, distribuídas ao longo de uma linha traçada no terço superior do papel, utilizando 10 sementes, com quatro repetições. A seguir, as sementes foram cobertas com uma terceira folha de papel, e enroladas e protegidas por saco plástico.

Após o tempo de cinco dias da instalação do teste, nas plântulas normais foi medido o comprimento da radícula e do hipocótilo, sendo os valores expressos em centímetros. 


\section{Crescimento de plantas}

Foram utilizadas as sementes de algodão armazenadas por 60 e 180 DAT, semeadas em vasos com 2,5 L de capacidade preenchidas com mistura contendo solo latossolo vermelho eutroférrico, $30 \%$ do volume em esterco de curral e $30 \%$ de areia. Foram distribuídas cinco sementes por vaso e, após a emergência, ocorreu o desbaste, deixando apenas uma planta por vaso, com quatro repetições. Após um período de 24 dias da emergência das plântulas, foi avaliada a altura da planta e da inserção do nó cotiledonar.

Para a avaliação da massa da matéria seca das folhas foi definida somente a lâmina foliar, após a remoção dos pecíolos, e caules considerando os pecíolos e as hastes, sendo os materiais acondicionados em sacos de papel e secos em estufas com circulação forçada de ar a $60^{\circ} \mathrm{C}$ até a obtenção da massa constante, medidas com o uso de balança de precisão de 0,001 g.

\section{Delineamento experimental}

O experimento foi montado utilizando o delineamento inteiramente casualizado, em esquema fatorial com quatro doses e cinco períodos de armazenamento, com quatro repetições para teste de germinação e inteiramente casualizado, com quatro repetições para os outros fatores analisados. Os resultados foram submetidos à análise de variância e a análise de regressão, com o emprego de polinômios ortogonais, utilizando o de melhor ajuste.

\section{RESULTADOS E DISCUSSÃO}

\section{Germinação}

O CM aplicado via embebição de semente, independentemente da dose utilizada, reduziu a capacidade germinativa (Figura 1). As sementes de algodão não tratadas com fitorregulador (dose zero) mantiveram a percentagem de germinação até os 180 dias de armazenamento. Esse resultado está de acordo com as informações de da Silva et al. (2006), que, avaliando o desempenho de sementes de algodão após processamento e armazenamento por até 120 dias após descaroçamento mecânico, verificaram que a percentagem de germinação das sementes manteve-se por até seis meses após a colheita, dentro dos padrões para o comércio (70\%). Para as doses de 2,5 e 5,0 g i.a. $\mathrm{kg}^{-1}$ de semente, a germinação foi mantida por um período de 60 dias após o tratamento sem redução, mantendo percentagem próxima de $80 \%$, obtendo uma redução de 0,0767 e $0,0984 \%$ para cada dia armazenado, respectivamente. Com dose de 10,0 g i.a. $\mathrm{kg}^{-1}$ de semente, este período reduziu para 30 dias com uma redução de $0,0682 \%$ para cada dia armazenada, com maior perda na germinação após este período.

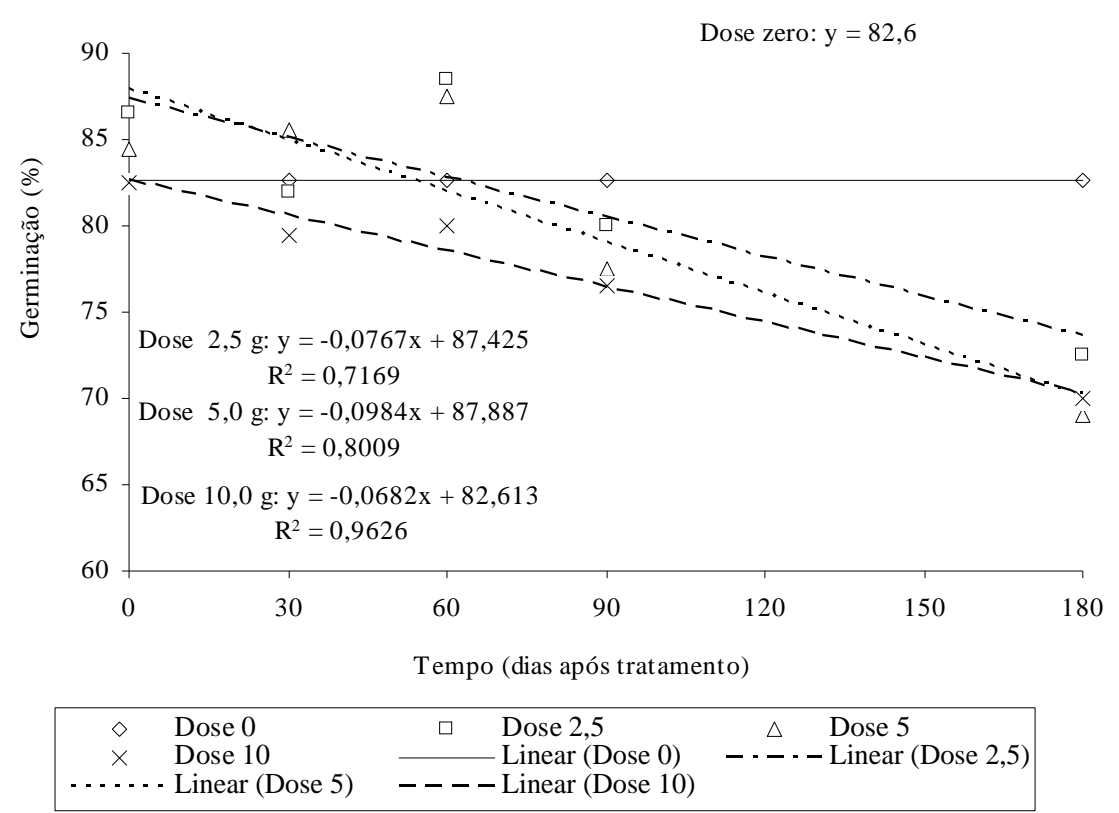

Figura 1 - Germinação de sementes de algodão em função das doses de embebição de cloreto de mepiquat (0; 2,5; 5,0 e 10,0 gramas do i.a. $\mathrm{kg}^{-1}$ de sementes) e do tempo de armazenamento (0, 30, 60, 90 e 180 dias após tratamento). Londrina, 2006. 
A germinação de sementes de algodão, considerando os efeitos dos tempos de armazenamento em função das doses utilizadas, ajustou-se a uma equação de regressão de primeiro grau, com uma redução de $0,7486 \%$ para cada grama do ingrediente ativo utilizado aos 90 e de segundo grau aos 180 DAT, obtendo a menor taxa de germinação com 6,98 g i.a. $\mathrm{kg}^{-1}$ de sementes, respectivamente (figura 2 ). Independente do tratamento (doses) na semente, o tempo zero não apresenta efeito na germinação, mantendo o percentual germinativo. Mesmo com tempos de armazenamento de 30 e 60 DAT e independente das doses utilizadas na embebição, apresentam as mesmas tendências de sementes com tempo zero, sem efeito redutor na germinação. Essas informações enfatizam o período da viabilidade de sementes que pode ser de até 60 dias sem efeito negativo na germinação.

\section{Comprimento da radícula e do hipocótilo}

A análise de plântulas em rolos de papel apresentou resultado significativo em função das doses de cloreto de mepiquat, somente na redução do comprimento total das plântulas (Tabela 1), não apresentando efeito no comprimento de radícula, comprovando assim que a embebição reduz a altura da planta já a partir da fase de plântula, mesmo antes da emergência. As plântulas possuem maior relação de raízes/parte aérea, este fator pode ser útil em condições de falta de umidade, logo após emergência de plântulas. Avaliando o efeito da aplicação foliar de diferentes doses de regulador de crescimento e desfolhante sobre o desempenho da semente produzida, Lamas \& Athayde (1999) concluem que as doses destes produtos não interferiram na germinação e no comprimento do hipocótilo.

A regressão apresentou efeito quadrático somente para o comprimento total de plântulas, exprimida pela equação $\mathrm{y}=19,4-1,4 \mathrm{x}+0,098 \mathrm{x}^{2}, \mathrm{R}^{2} 0,99$. O menor comprimento total de plântula ocorreu com dose de $7,14 \mathrm{~g}$ i.a. $\mathrm{kg}^{-1}$ de sementes.

\section{Crescimento de plantas}

O experimento conduzido em casa de vegetação, para verificação da manutenção do efeito redutor em plantas originadas de sementes embebidas em CM e armazenadas por 60 e 180 DAT, mostrou efeito das doses nos fatores avaliados.

A altura de plantas e da inserção do nó cotiledonar foi afetada pelos tratamentos de embebição de sementes com cloreto de mepiquat. Com a diminuição do porte da planta, desde a emergência, o efeito redutor foi mais significativo, principalmente, para maiores doses (Tabela 2), conforme verificado por Nagashima et al. (2005) que obtiveram a redução na altura da planta de algodão diretamente proporcional à dose aplicada, portanto, quanto maior a dose do produto, menor o porte da planta. Corbin \& Frans (1991), que testaram o efeito de $1000 \mathrm{ppm}$ de cloreto de mepiquat e cloreto de clormequat no tratamento de semente para reduzir o efeito negativo do uso de Fluometuron (herbicida), constataram que a altura das plantas foi reduzida até três semanas após a semeadura, com recuperação do crescimento dessas plantas nove semanas após o plantio. Lamas (2006) comprovou pelos resultados obtidos que o $\mathrm{CM}$ em mistura com fungicidas reduziram a altura de plantas, quando as sementes foram tratadas com essas misturas.

A regressão para altura de plantas aos 60 DAT apresentou redução do porte com efeito quadrático, segundo a equação $y=17,4-3,3 x+0,2216 x^{2}$, com $R^{2}$ de 0,985 e apresentando o menor porte com a dose de 7,4 gramas do ingrediente ativo por quilograma de semente. Plantas originadas de sementes embebidas e armazenadas por 180 dias não apresentaram diferença no porte entre as doses utilizadas na embebição, somente quando comparadas com dose zero e apresentaram efeito cúbico segundo a equação $\mathrm{y}=18,3-8,2 \mathrm{x}+1,75 \mathrm{x}^{2}-$ $0,10 x^{3}, R^{2}$ de 1,0 . A altura da inserção do nó cotiledonar também foi reduzida apresentando efeito quadrático, segundo a equação $y=10,8-2,0 x+0,134 x^{2}$, com $R^{2}$ de 0,99 tendo a menor altura de inserção do nó cotiledonar com a dose de 7,4 g i.a. $\mathrm{kg}^{-1}$ de sementes. Com armazenamento por 180 dias, a redução na inserção da folha cotiledonar teve ajuste cúbico, ajustada a uma equação de $y=9,6-3,9 x+0,8 x^{2}-0,046 x^{3}$, com $R^{2}$ de 1,0 . Baseados nos resultados obtidos, com o armazenamento, há redução da qualidade fisiológica da semente quando embebidas em solução contendo CM, mesmo com doses menores do regulador.

$\mathrm{O}$ efeito do cloreto de mepiquat via embebição, sobre a área foliar e massa da matéria seca de caules foi significativo, apresentando efeito linear e quadrático significativo. (Tabela 3).

As reduções verificadas na área foliar e massa da matéria seca de caules e folhas estão de acordo com Nagashima et al. (2005) que trataram as sementes com cloreto de mepiquat via embebição e Zhao \& Oosterhuis (2000) que utilizaram o produto via aplicação foliar. Quando submetidos à análise de regressão, a área foliar aos 60 DAT apresentou ajuste linear apresentando equação $y=133,8-6,5 x$, com redução da área de $6,5 \mathrm{~cm}^{2}$ para cada grama do produto utilizado, e ajuste quadrático aos 180 
DAT, baseado na equação $y=176,6-26,0 x+1,79 x^{2}$ e $R^{2}$ de 0,94, com menor área com a dose de 7,26 g i.a. $\mathrm{kg}^{-1}$ de sementes.

A massa da matéria seca de folhas teve ajuste quadrático e cúbico para 60 e 180 DAT, respectivamente, apresentando as seguintes equações: $\mathrm{y}=0,618-0,077 \mathrm{x}+$ $0,0432 x^{2}\left(R^{2}=0,97\right)$ e y $=0,853-0,288 x+0,60 x^{2}-0,00357 x^{3}$ $\left(\mathrm{R}^{2}=1,0\right)$ apresentando menor massa da matéria seca de folhas aos 60 dias com a dose de 8,91 g i.a. $\mathrm{kg}^{-1}$ de sementes. A massa da matéria seca de caules teve ajuste quadrático para 60 DAT e cúbico para $180 \mathrm{DAT}$, ajustadas às equações $\mathrm{y}=0,316-0,0616 \mathrm{x}+0,00395 \mathrm{x}^{2} \mathrm{e}$ $y=0,507-0,236 x+0,049 x^{2}-0,00294 x^{3}$, respectivamente, com $\mathrm{R}^{2}$ de 1,0 . A menor massa da matéria seca de caules aos 60 DAT foi obtida com dose de 7,8 g i.a. $\mathrm{kg}^{-1}$ de sementes.

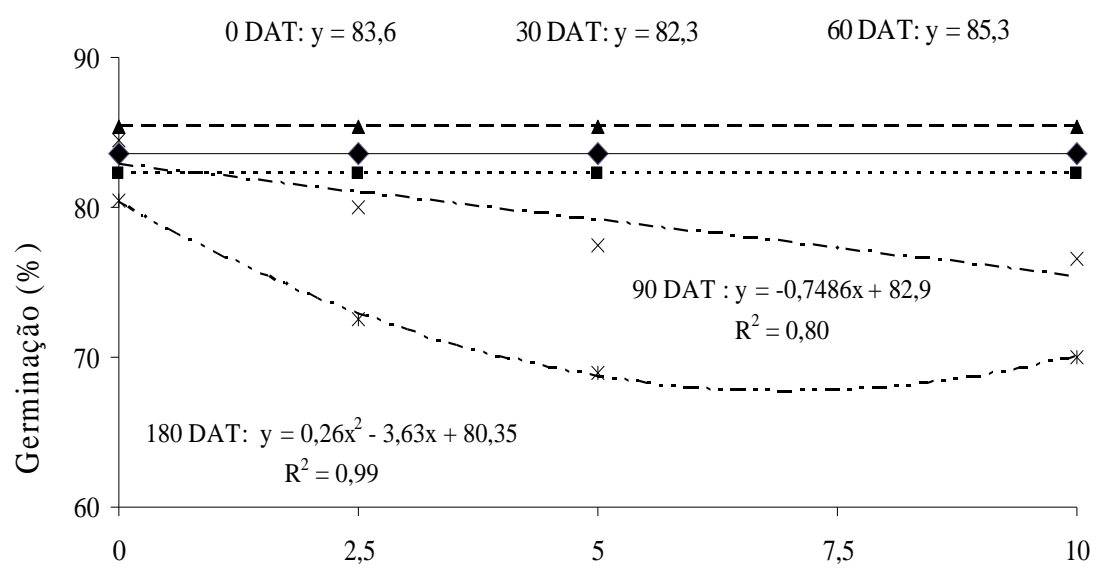

Doses (g i.a. $\mathrm{kg}^{-1}$ semente)

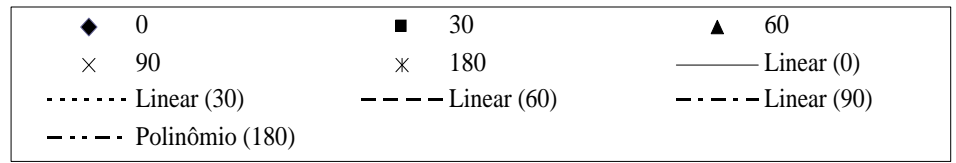

Figura 2 - Germinação de sementes de algodão aos zero, 30, 60, 90 e 180 dias após tratamento em função das doses de embebição de cloreto de mepiquat (i.a. $\mathrm{kg}^{-1}$ de sementes), Londrina, 2006.

Tabela 1 - Comprimento total e da radícula de plântulas originadas de sementes embebidas em Cloreto de Mepiquat nas doses de zero; 2,5; 5,0 e 10,0 gramas do ingrediente ativo por kg de sementes aos cinco dias do início da emergência, armazenadas por 60 dias, Londrina, 2006

\begin{tabular}{lcc}
\hline & \multicolumn{2}{c}{ Comprimento (cm) } \\
\hline Doses (g i.a. $\mathrm{kg}^{-1}$ sementes) & Total & Radícula \\
\cline { 2 - 3 } Zero & 19,4 & 12,5 \\
2,5 & 16,5 & 11,4 \\
5,0 & 14,9 & 11,0 \\
10,0 & 15,3 & 11,3 \\
\hline DMS & 3,7 & 3,0 \\
C.V. $(\%)$ & 10,64 & 12,29 \\
\hline F & $5,3^{*}$ & $0,9 \mathrm{~ns}$ \\
F linear & $9,74 * *$ & $1,26 \mathrm{~ns}$ \\
F quadrática & $6,14^{*}$ & $1,27 \mathrm{~ns}$ \\
F cúbica & $0,002 \mathrm{~ns}$ & $0,026 \mathrm{~ns}$ \\
\hline
\end{tabular}

ns, $* * e^{*}=$ não significativo, significativo a 1 e $5 \%$, respectivamente. 
Tabela 2 - Altura média da planta e da inserção do nó cotiledonar em plantas originadas de sementes embebidas em cloreto de mepiquat nas doses de zero; 2,5; 5,0 e 10,0 gramas do ingrediente ativo por kg de sementes aos 24 dias após emergência, armazenadas por 60 e 180 dias, Londrina, 2006.

\begin{tabular}{lcccc}
\hline & \multicolumn{2}{c}{ Altura $(\mathrm{cm})$ aos 60 DAT } & \multicolumn{2}{c}{ Altura $(\mathrm{cm})$ aos 180 DAT } \\
\cline { 2 - 5 } $\begin{array}{l}\text { Doses }(\mathrm{g} \text { i.a.kg } \\
\text { semente) }\end{array}$ & Planta & $\begin{array}{c}\text { Inserção nó } \\
\text { cotiledonar }\end{array}$ & Planta & $\begin{array}{c}\text { Inserção nó } \\
\text { cotiledonar }\end{array}$ \\
\hline Zero & 17,8 & 11,0 & 18,3 & 9,6 \\
2,5 & 9,7 & 6,4 & 8,1 & 4,0 \\
5,0 & 7,1 & 4,8 & 7,2 & 4,0 \\
10,0 & 6,4 & 4,7 & 6,6 & 3,7 \\
\hline DMS & 2,4 & 1,4 & 2,5 & 1,2 \\
C.V. $(\%)$ & 14,24 & 13,03 & 13,85 & 12,42 \\
\hline F & $76,6 * *$ & $79,1 * *$ & $93,0^{* *}$ \\
F linear & $158,2 * *$ & $13,1 * *$ & $143,3^{* *}$ \\
F quadrática & $68,1 * *$ & $69,0 * *$ & $76,3, * *$ & $105,5^{* *}$ \\
F cúbica & $3,4 \mathrm{~ns}$ & $2,8 \mathrm{~ns}$ & $36,2 * *$ & $30,4^{* *}$ \\
\hline
\end{tabular}

** e * significativo a 1 e $5 \%$, respectivamente; DAT = dias após tratamento.

Tabela 3 - Área foliar, massa da matéria seca de folhas e caules em plantas originadas de sementes embebidas em cloreto de mepiquat nas doses de zero; 2,5; 5,0 e 10,0 gramas do ingrediente ativo por kg de sementes aos 24 dias após emergência, armazenadas por 60 e 180 dias, Londrina, 2006.

\begin{tabular}{lcccccc}
\hline & \multicolumn{2}{c}{ Área foliar $\left(\mathrm{cm}^{2}\right)$} & \multicolumn{2}{c}{ Massa da matéria seca $(\mathrm{g})$} \\
\cline { 2 - 7 } $\begin{array}{l}\text { Dose (g i.a. } \\
\mathrm{kg}^{-1} \text { sementes) }\end{array}$ & 60 DAT & 180 DAT & Folha 60 DAT & $\begin{array}{c}\text { Folha 180 } \\
\text { DAT }\end{array}$ & $\begin{array}{c}\text { Caule 60 DAT } \\
\text { Caule 180 } \\
\text { DAT }\end{array}$ \\
\hline Zero & 134,7 & 181,6 & 0,63 & 0,85 & 0,32 & 0,51 \\
2,5 & 98,3 & 109,4 & 0,42 & 0,46 & 0,18 & 0,20 \\
5,0 & 79,7 & 101,2 & 0,36 & 0,45 & 0,11 & 0,18 \\
10,0 & 65,8 & 93,4 & 0,27 & 0,39 & 0,09 & 0,15 \\
\hline DMS & 39,2 & 54,3 & 0,18 & 0,25 & 0,08 & 0,16 \\
C.V. $(\%)$ & 25,6 & 24,7 & 25,9 & 25,3 & 27,9 & 33,1 \\
\hline F & $9,1^{* *}$ & $9,2^{* *}$ & $11,6^{* *}$ & $12,2^{* *}$ & $25,6^{* *}$ & $18,6^{* *}$ \\
F linear & $23,3^{* *}$ & $17,2^{* *}$ & $22,0^{* *}$ & $22,1^{* *}$ & $57,3^{* *}$ & $30,2^{* *}$ \\
F quadrática & $3,9 \mathrm{~ns}$ & $8,7 * *$ & $4,6^{*}$ & $9,9^{* *}$ & $18,9 * *$ & $18,0^{* *}$ \\
F cúbica & $0,08 \mathrm{~ns}$ & $1,70 \mathrm{~ns}$ & $0,98 \mathrm{~ns}$ & $4,40^{*}$ & $0,38 \mathrm{~ns}$ & $7,46^{*}$ \\
\hline
\end{tabular}

** e * = significativo a 1 e $5 \%$, respectivamente; DAT = dias após tratamento.

\section{CONCLUSÕES}

As sementes de algodão embebidas com cloreto de mepiquat podem ser armazenadas por 60 dias, após o tratamento com doses de até 10,0 gramas do i.a kg-1 de sementes, sem causar danos na qualidade fisiológica;

Plântulas originadas de sementes embebidas com cloreto de mepiquat apresentam crescimento menor, antes mesmo da emergência;
$\mathrm{O}$ efeito redutor do cloreto de mepiquat embebidos em sementes de algodão persiste por, pelo menos, 180 dias após o tratamento.

\section{AGRADECIMENTOS}

À Coordenação de Aperfeiçoamento de Pessoal de Nível Superior (CAPES) pela concessão de bolsa ao primeiro autor e ao Conselho Nacional de Desenvolvimento Científico e Tecnológico (CNPq) ao último autor. 


\section{REFERÊNCIAS BIBLIOGRÁFICAS}

BRASIL. Ministério da Agricultura. Regras para análise de sementes. 2.ed. Brasília: Departamento Nacional de Produção Vegetal, 1992. 182p.

CORBIN JUNIOR, B.R.; FRANS, R.E. Protecting cotton (Gossypium hirsutum) from Fluometuron injury with seed protectants. Weed Science, Champaign, v.39, p.408411, July/Sept. 1991.

HODGES, H.F.; REDDY, V.R.; REDDY, K.R. Mepiquat chloride and temperature effects on photosynthesis and respiration of fruiting cotton. Crop Science, Madison, v.31, n.5, p.1302-1308, Sept./Oct. 1991.

LACA-BUENDIA, J.P. Efeito de doses de reguladores de crescimento no algodoeiro (Gossypium hirsutum L.). Revista Brasileira de Fisiologia Vegetal, Brasília, v.1, n.1, p.109-113, 1989.

LAMAS, F.M. Estudo comparativo entre cloreto de mepiquat e cloreto de chlormequat aplicados no algodoeiro. Pesquisa Agropecuária Brasileira, Brasília, v.36, n.2, p.265-272, fev. 2001.

\section{LAMAS, F.M. Cloreto de mepiquat na cultura do} algodoeiro via sementes. Dourados: Embrapa Agropecuária Oeste, 2006. (Boletim de Pesquisa e Desenvolvimento, 33).

LAMAS, F.M.; ATHAYDE, M.L.F. Efeito do cloreto de mepiquat e do thidiazuron sobre algumas características das sementes do algodoeiro. Pesquisa Agropecuária Brasileira, Brasília, v.34, n.11, p.20152019, nov. 1999.
NAGASHIMA, G.T.; MARUR, J.C.; YAMAOKA, S.R.; MIGLIORANZA, É. Desenvolvimento de plantas de algodão provenientes de sementes embebidas em cloreto de mepiquat. Pesquisa Agropecuária Brasileira, Brasília, v.40, n.9, p.943-946, 2005.

NAGASHIMA, G.T.; MIGLIORANZA, É.; MARUR, C.L.; YAMAOKA, R.S.; GOMES, J.C. Embebição de sementes e aplicação foliar com cloreto de mepiquat no crescimento e produção do algodoeiro. Ciência e Agrotecnologia, Lavras, v.31, n.4, p.1027-1034, 2007.

RIGHI, N.R.; FERRAZ, C.A.M.; CORRÊA, D.M. Cultura. In: NEVES, O. da S. et al. Cultura e Adubação do Algodoeiro. São Paulo: Instituto Brasileiro da Potassa, 1965. p.255-317.

SILVA, J.C. da; ALBUQUERQUE, M.C.; MENDONÇA, E.A.F. de; KIM, M.E. Desempenho das sementes de algodão após processamento e armazenamento. Revista Brasileira de Sementes, Pelotas, v.28, n.1, p.79-85, 2006.

XU, X.; TAYLOR, H.M. Increase in drought resistance of cotton seedlings treated with mepiquat chloride. Agronomy Journal, Madison, v.84, p.569-574, July/Aug. 1992.

YEATS, S.J.; CONSTABLE, G.A.; McCUMSTIE, T. Cotton growth and yield after seed treatment with mepiquat chloride in the tropical winter season. Field Crops Research, Amsterdam, v.93, n.2/3, p.122-131, 2005.

ZHAO, D.; OOSTERHUIS, D.M. Pix Plus and mepiqaut chloride effects on physiology, growth, and yield of field-grown cotton. Journal of Plant Growth Regulation, n.19, p.415-422, 2000. 